UCRL-ID-133365

\title{
Impurity Leaching Rates of 1000 Liter Growth Tanks
}

\author{
Harry Robey \\ Randy Floyd \\ Rich Torres \\ Alan Burnham
}

February 19, 1999

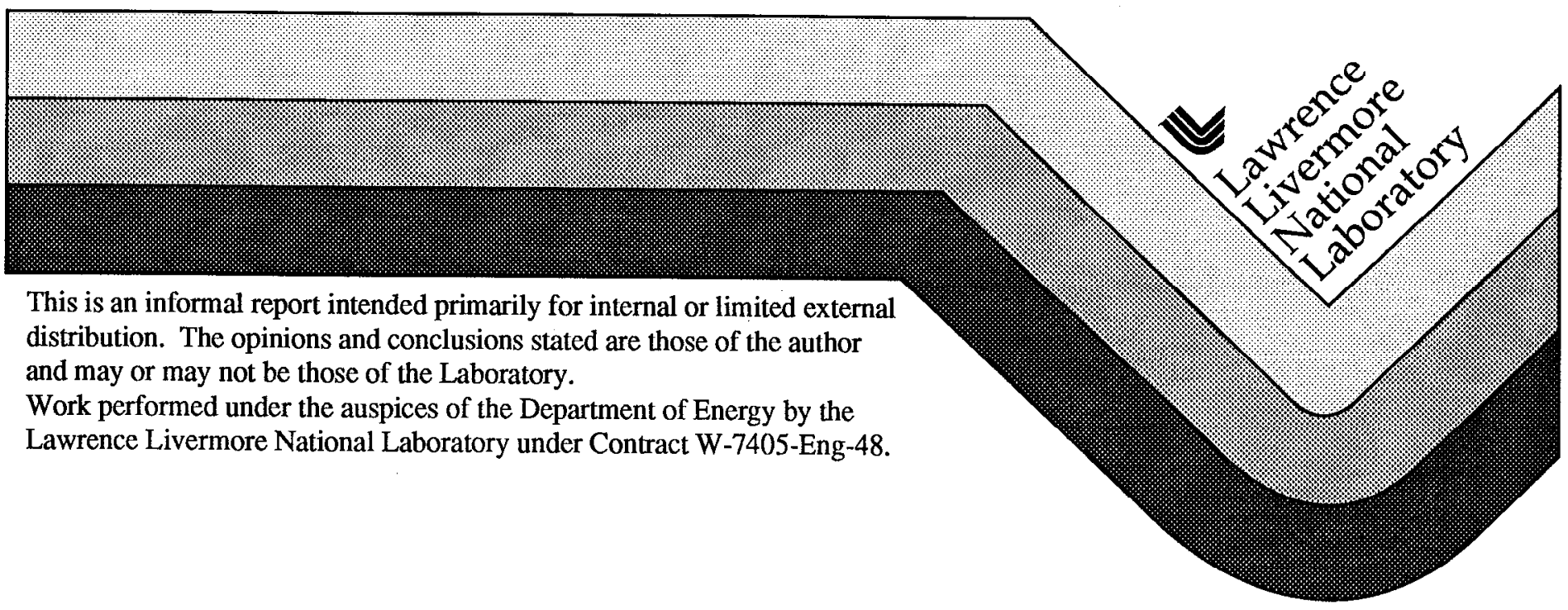




\section{DISCLAIMER}

This document was prepared as an account of work sponsored by an agency of the United States Government. Neither the United States Government nor the University of California nor any of their employees, makes any warranty, express or implied, or assumes any legal liability or responsibility for the accuracy, completeness, or usefulness of any information, apparatus, product, or process disclosed, or represents that its use would not infringe privately owned rights. Reference herein to any specific commercial product, process, or service by trade name, trademark, manufacturer, or otherwise, does not necessarily constitute or imply its endorsement, recommendation, or favoring by the United States Government or the University of Califomia. The views and opinions of authors expressed herein do not necessarily state or reflect those of the United States Government or the University of California, and shall not be used for advertising or product endorsement purposes.

This report has been reproduced directly from the best avalable copy.

Available to DOE and DOE contractors from the Office of Scientific and Technical Information P.O. Box 62, Oak Ridge, TN 37831

Prices available from (615) 576-8401, FTS 626-8401

Available to the public from the

National Technical Information Service

U.S. Department of Commerce 5285 Port Royal Rd., Springfield, VA 22161 


\title{
Impurity leaching rates of 1000 liter growth tanks
}

\author{
Harry Robey, Randy Floyd, Rich Torres and Alan Burnham
}

\author{
Lawrence Livermore National Laboratory \\ Livermore, CA 94551
}

\section{Summary}

This memo reports on the analysis of some recent measurements of solution impurity levels in the three KDP and one DKDP Pilot Production 1000 liter growth tanks (Tanks B, C, D, \& F). Solution samples were taken on a weekly basis during recent crystal growth runs in each tank and were analyzed by inductively coupled plasma emission spectroscopy (ICP-ES). The solution history for five specific elements, $\mathrm{Si}, \mathrm{B}$, $\mathrm{Al}, \mathrm{Fe}$ and $\mathrm{Ca}$ will be analyzed in detail. The first four of these elements are input into solution via slow dissolution of the glass vessel at a rate which is strongly dependent on the solution temperature. Si and B continuously accumulate in solution, since they are not incorporated into the crystal. $\mathrm{Al}$ and $\mathrm{Fe}$ by comparison are incorporated into the crystal (primarily the prismatic sectors) and present problems to inclusion-free growth $(\mathrm{Al})$ and $3 \omega$ damage $(\mathrm{Fe})$. The level of these impurities initially increases when the crystal size is small but later decreases when the rate of incorporation into the crystal exceeds the rate of dissolution of the glass tank. The last element, $\mathrm{Ca}$ is of interest since it has recently been observed to be one of the elements found at the location of $3 \omega$ damage.

For $\mathrm{Si}$ and $\mathrm{B}$, the dissolution or leach rate from the glass tank is easily obtained from the results of the chemical analysis. The temperature dependent leach rates are shown to be comparable (within a factor of two) for all four tanks, with Tank B (DKDP) having the lowest rate of $\mathrm{Si}$ accumulation. The glass leach rates of the two incorporating elements $\mathrm{Al}$ and $\mathrm{Fe}$ require substantially more analysis as the daily variation of the crystal dimensions, the solution concentration, and the mass of $\mathrm{KDP}$ remaining in solution must be taken into account in order to separate the rate of impurity incorporation from the rate of dissolution of the glass. The method for accomplishing this separation is described, and the result obtained is that the leach rates of all four tanks are within a factor of three of each other. Tank B again shows the lowest leach rate for both Al and Fe.

The results for $\mathrm{Ca}$ are less clear. From the present data, the level of $\mathrm{Ca}$ does not change appreciably during a run, indicating that it is neither leaching from the glass strongly nor being incorporated into the crystal at a significant rate. It does increase with the age of the solution, however, as $\mathrm{Ca}$ is a small but measurable component of both the starting salt as well as the $\mathrm{D}_{2} \mathrm{O}$. Older solutions that have successfully grown several 
crystals will therefore have higher accumulated levels of $\mathrm{Ca}$, which will increase the driving force for $\mathrm{Ca}$ incorporation into the crystal.

\section{Data Analysis}

\section{Data summary for $\mathrm{Si}, \mathrm{B}, \mathrm{Ca}, \mathrm{Al}, \mathrm{Fe}, \mathrm{Cr}$, and $\mathrm{Ba}$}

The following Tables summarize the level of 7 impurities taken from the most recent growth runs in Tanks B, C, D, and F. All of the data are obtained from samples extracted from the continuous filtration system (CFS) during growth runs. Tank $\mathrm{B}$ is unique in that it has a deuterated solution and uses an acrylic platform operating at a relatively low rotation rate $(25 \mathrm{rpm})$. All other tanks $(\mathrm{C}, \mathrm{D}, \& \mathrm{~F})$ are ordinary $\mathrm{KDP}$, and the crystals are grown on aluminum platforms operating at higher rotation rates $(50 \mathrm{rpm})$. All aluminum platforms are hard anodized and coated with 6 topcoats of Halar (8014). Precision tick marks are etched into the anodized coating below the Halar to enable very accurate measurement $(<1 \mathrm{~mm})$ of all prismatic face dimensions. The platform in Tank $\mathrm{D}$ has a convex surface, while the other two are flat.

The elements examined in detail are $\mathrm{Si}, \mathrm{B}, \mathrm{Ca}, \mathrm{Al}, \mathrm{Fe}, \mathrm{Cr}$, and $\mathrm{Ba}$. The first three of these are taken as examples of elements which are generally not believed to incorporate strongly into the crystal, according to previous data [Zaitseva et. al., 1998]. However, Ca was recently observed to be one of the elements found at the location of $3 \omega$ damage [DeYoreo, personal communication]. The last four do incorporate into the crystal. All of these can create problems with inclusion-free growth of prismatic faces, and $\mathrm{Fe}$ is also thought to be a source of damage at $3 \omega$ if in nanoparticle form because of the high absorption coefficient of $\mathrm{FePO}_{4}$.

Table 1 gives the relative solution impurity levels as $g_{\text {impurity }} / \mathrm{g}_{\mathrm{KDP}}$ in $\mathrm{ppb}$. In these tables, the number on the first line in parentheses is the detection limit for that element in ppb. A "D" indicates that the element is just at this detection limit, and "ND" indicates that it is not detected. Since a crystal is being grown from all of these solutions, the amount of KDP in solution decreases continuously throughout a run. For this reason, the impurity levels are also listed in Table 2 as grams of each impurity.

From Tables 1 and 2, several of the elements can be eliminated from further consideration. $\mathrm{Cr}$, for example, is non-detectable in all tanks throughout the duration of the run. $\mathrm{Ba}$ is detected but at levels far below the rapid growth specification of $500 \mathrm{ppb}$. This leaves $\mathrm{Si}, \mathrm{B}, \mathrm{Al}, \mathrm{Fe}$, and $\mathrm{Ca}$ for further analysis.

\section{Analysis of non-incorporating elements, Si and B}

From Tables 1 and 2, it is seen that in all tanks the levels of Si and B continuously increase with time. In order to determine the leaching rate of these elements from the glass tank, the absolute levels of Table 2 must be used. Figure 1 shows a plot of the absolute levels of both Si and B in these four tanks. Tank B has the highest level of Si, followed by Tanks C, F, and D respectively. The overall level correlates directly with the age of the solution. The date that the solution was initially prepared is given in Tables 1 and 2 as the solution $\log \#$ in the format (year:month:day). The solution of Tank B was prepared in January, Tank C in May, Tank F in October, and Tank D in November. 
Since neither Si nor B are incorporated into the crystal, they accumulate from run to run in a given solution.

The leach rate of these impurities decreases with time throughout the run, since the solution temperature is decreased to maintain a nearly constant concentration difference $\left(\mathrm{C}-\mathrm{C}_{\mathrm{e}}\right)$ as the crystal grows. The lower figure plots the leach rate as the time rate of change in $\mathrm{g}_{\mathrm{S}, \mathrm{B}}$ / day vs. the decreasing solution temperature. In this way, the leach rates of the different tanks are normalized for temperature dependence. The leach rates are seen to decrease with temperature and are generally within a factor of two for all tanks. The data for Tank B have quite a bit of scatter, since the changes are less than the $10 \%$ accuracy of the measurements for these high impurity levels. The data for Tanks $\mathrm{C}$ and $\mathrm{F}$ have a much better signal-to-noise level and can therefore be used to determine rate coefficients. The data are fit to a rate expression of the form :

$$
\text { rate }=A \cdot \exp (-B / T)
$$

where $\mathrm{A}$ and $\mathrm{B}=\mathrm{E} / \mathrm{R}$ are the constants to be fit, and $\mathrm{E}$ is the activation energy in kcal / mole and $\mathrm{R}=1.987 \mathrm{kcal} /\left(\right.$ mole ${ }^{\circ} \mathrm{K}$ ) is a constant. The temperature $\mathrm{T}$ is in ${ }^{\circ} \mathrm{K}$. The activation energy determined by this curve fit is $16054 \mathrm{kcal} /$ mole. The data for $\mathrm{B}$ are qualitatively similar to $\mathrm{Si}$, though the leaching rate is at a lower level.

\section{Analysis of Al impurity levels}

Determination of the leach rate of the elements which incorporate into the crystal is more difficult since there is now both a source (the glass) and a sink (the crystal). The procedure that was followed to separate these two contributions is the following. It is assumed that the leach rate from the glass follows a rate expression of the form of eqn. (1). The coefficients $A$ and $B$ were determined from previous leaching experiments performed in 5 liter glass vessels over a 12 week period at temperatures of $60^{\circ} \mathrm{C}$ and $80^{\circ} \mathrm{C}$. During these tests, no crystal was grown The activation cnergy determined from these measurements is $18303 \mathrm{kcal} /$ mole, and the coefficient $\mathrm{A}=3.107 \times 10^{9} \mathrm{~g}_{\mathrm{Al}} /$ day.

The incorporation into the crystal is assumed to depend on a segregation coefficient $\mathrm{S}$, where $\mathrm{S}$ is defined as the ratio of $\mathrm{Al}$ concentration in the crystal to that in the solution:

$$
S=\frac{\left(g_{A l} / g_{K D P}\right)_{\text {crystal }}}{\left(g_{A l} / g_{K D P}\right)_{s o l}}
$$

The segregation coefficient is not a well characterized quantity. For aluminum, the value is taken to be approximately 5 [Zaitseva et. al., 1998]. Throughout this report, we will use $S=5$. We will also assume for simplicity that aluminum is only incorporated into the prismatic sectors, and not into the pyramid. This is a reasonable first approximation, since the segregation coefficient for the pyramids is of the order 0.2. Knowing the solution concentration, the mass of prismatic material added in a given time interval, and using this assumed value for the segregation coefficient gives an estimate of the number of grams of impurity incorporated into this element of the prism at any time. Knowing the solution temperature gives the number of grams of impurity added to the solution 
from the glass. All of these variables are measured on a daily basis and are recorded in the LLNL KDP Crystal Growth Electronic Log Book [Robey et. al., 1998].

Figure 2 shows an example of using the data in the log book to estimate the aluminum concentration throughout a growth run. The segregation coefficient and activation energy are held constant, while the rate coefficient $A$ in eqn. (1) is adjusted to obtain the best fit to the measured impurity levels. This coefficient $\mathrm{A}$ is expected to vary from tank to tank due to differences in the glass composition. The agreement between this method and the measurements obtained by chemical analysis of the samples withdrawn from the CFS are quite good. The glass leach rate can now be isolated by setting the segregation coefficient to zero, and using the temperature data in the log book together with the rate equation. The lower plot in Figure 2 shows this rate given in ppb / day plotted vs. decreasing solution temperature.

This same procedure is applied to each of the tanks. The results for Tank B are shown in Figure 3. By comparison with the data for Tank F, it can be seen that the rate of accumulation of aluminum is significantly smaller for Tank B vs. Tank F. A large portion of this difference is due to the different growth temperatures of the two tanks (DKDP grows at lower temperature than KDP due to its higher solubility). This temperature difference can be normalized by plotting the leach rates vs. temperature as shown in Figure 4. The leach rate is plotted for all tanks both as ppb/day (top plot) and as grams / day (bottom plot). The lower plot is perhaps more useful for comparing KDP and DKDP runs as it also normalizes the different solution masses. (The curve fits for Tanks $\mathrm{C}$ and $\mathrm{D}$ used to determine the rate coefficients for those tanks arc included in Appendix A. These runs are still ongoing, and the curve fits will improve with additional data.) From Figure 4, it can be seen that the leach rates of all tanks are approximately within a factor of two of each other. Tank B clearly has the lowest rate. Several possible explanations for this difference are given in the Discussion Section.

\section{Analysis of Fe impurity levels}

The analysis of the Fe impurity levels is identical to that used for Al. The activation energy, again obtained from controlled leaching experiments in 5 liter tanks, was 11322 $\mathrm{kcal} /$ mole. As was the case for $\mathrm{Al}$, the segregation coefficient for $\mathrm{Fe}$ is not a well characterized quantity. It is known to depend on both the starting solution impurity level as well as the crystal growth rate [Yan et. al., 1996]. In [Zaitseva et. al., 1998], a value of $S=2.3$ is given, though this value comes from an experiment with a highly doped $\mathrm{Fe}$ concentration of $5.3 \mathrm{ppm}$. At lower impurity concentrations, the segregation coefficient is likely to be somewhat higher. Lacking a well characterized value, the segregation coefficient will again be taken to be $S=5$. The curve fits used to determine the rate coefficients and the associated leach rates vs. temperature are shown for tanks F and B in Figures 5 and 6, respectively. The Fe levels are lower by approximately one order of magnitude as compared with those of aluminum. The impurity level again reaches a maximum in 20 - 35 days after which it begins to decrease. Note that for both $\mathrm{Al}$ and $\mathrm{Fe}$ the impurity levels reach a maximum sooner in Tank F (20-25 days) than they do in Tank $\mathrm{B}$ (35 days). The reason for this is that the crystal in Tank F was grown at a considerably higher rate than the crystal in Tank B due to the difference in support platform technology (aluminum in Tank F vs. acrylic in Tank B). A crystal grown at a higher rate will begin to clean up the solution sooner. Figure 7 shows plots of the comparative leach rates for all tanks. Again, the lower plot is more useful, as it accounts for the solubility 
difference between KDP and DKDP. There is more variation between the KDP tanks (C, $\mathrm{D}$, and $\mathrm{F}$ ) than was observed for $\mathrm{Al}$, but at any given temperature the leach rates are still within a factor of three of each other. The greater tank-to-tank variability is probably attributed to the lower signal-to-noise level relative to the Al data. Again, Tank B is the cleanest of the tanks.

\section{Analysis of Ca impurity levels}

Figurc 8 shows a plot of the Ca accumulation (in grams) for each tank. The time history of $\mathrm{Ca}$ reveals a relatively constant level for each tank throughout the run. This behavior is different than that observed for $\mathrm{Si}$ and $\mathrm{B}$ which continually increase throughout a run and is also different than that observed for $\mathrm{Al}$ and $\mathrm{Fe}$ which increase to a maximum and then decrease until the end of the run. The absolute level is different for each tank, and as was the case with the $\mathrm{Si}$ accumulation, correlates directly with the age of the solution. The solution in Tank B having grown several crystals and being resaturated each time has the highest accumulation of Ca. Successively newer solutions (C, F, \& then D) have correspondingly lower $\mathrm{Ca}$ levels. In Tank $\mathrm{B}$, the $\mathrm{Ca}$ level is greater than the $\mathrm{Al}$ level due to this long term accumulation.

This data would suggest that $\mathrm{Ca}$ is neither leaching appreciably from the glass tank nor incorporating strongly into the crystal. It is simply accumulating in solution with each resaturation. The measurements reported in ref. [1] showed that even for a $\mathrm{Ca}$ level of $3600 \mathrm{ppb}$, no Ca was detectable in either the prism or the pyramid. For the stated detection limit of $100 \mathrm{ppb}$, this sets a maximum for the segregation coefficient at approximately 0.03 . If $\mathrm{Ca}$ is determined to be a problem for $3 \omega$ damage, then even for a very small segregation coefficient, this continuous accumulation of $\mathrm{Ca}$ in a solution may present a problem.

\section{Discussion}

This memo has shown three different characteristic impurity behaviors. Si and B give an example of elements which are leached from the glass tank but do not incorporate into the crystal (source, but no sink). They accumulate in solution both during a run as well as at each new resaturation. $\mathrm{Al}$ and $\mathrm{Fe}$ are both input into solution by dissolution of the glass and incorporated into the crystal prismatic sectors (source and sink). Their levels initially increase to a maximum at approximately 20-35 days and then decrease. $\mathrm{Ca}$ neither leaches nor incorporates into the crystal strongly (no source, no sink), and only accumulates through resaturations of the solution.

The examination of the elements which are leached from the glass shows some variation from tank to tank. In general, Tank B has the lowest rates for most species. There are several possible reasons for this observation. The simplest possible explanation would be that this tank was manufactured from raw material of higher purity and therefore has the lowest impurity content. This could be confirmed by chemical analysis of a small sample taken from the tank wall.

Another possible difference is that Tank B currently has an acrylic rather than an aluminum platform. This possibility is ruled out, however, for two reasons. First, the presence of an aluminum platform would not affect the leaching rate of $\mathrm{Fe}$, which is also the lowest in Tank B. Secondly, the amount of aluminum introduced into solution was 
measured over a one month period in a Teflon vessel with no crystal growth to complicate the measurements. In these controlled experiments [Robey, DeHaven, et. al.], several Halar coated $\mathrm{Al}$ test samples with the same surface area to solution volume ratio as the $1000 \mathrm{~L}$ tanks were maintained in $\mathrm{KDP}$ solution at $80^{\circ} \mathrm{C}$ for one month. The change in $\mathrm{Al}$ concentration over the full duration of the experiment was at or below the detection limit of $100 \mathrm{ppb}$. The aluminum growth platforms could therefore contribute a maximum of only $3.3 \mathrm{ppb} /$ day to the solution Al level. This is too small to account for the difference observed in Figure 4.

A related possibility involves the difference in rotation rate between the acrylic platform in Tank B which is constrained to operate at $25 \mathrm{rpm}$ or less and the $45-50 \mathrm{rpm}$ rotation rate used in all of the other tanks. The higher platform rotation rates used in Tanks C, D, and F will generate a higher shear stress at the tanks walls. As is well known from any standard textbook on heat or mass transfer, the rate of mass transfer will increase with this increase in shear at the wall. This possibility will be tested in the next growth run in Tank B which will use an aluminum platform operating at $50 \mathrm{rpm}$.

A final possibility is a difference in the $\mathrm{pH}$ of a deuterated vs. an ordinary KDP solution. The $\mathrm{pH}$ of ordinary $\mathrm{KDP}$ solutions is known to be a function of both the concentration and the temperature [Rashkovich, 1998]. For example, the $\mathrm{pH}$ decreases by approximately 0.1 for every $10^{\circ} \mathrm{C}$ increase in the solution temperature. This would suggest that KDP solutions which are maintained at higher tempcratures than DKDP solutions would be slightly more acidic and would therefore cause a higher rate of dissolution of the glass. On the other hand, an increase in solution concentration also decreases the $\mathrm{pH}$. This would argue that a DKDP solution with its higher solubility would be more acidic than KDP, and would therefore cause more dissolution of the glass. At present, this effect is pure speculation, and a measurement would be required to confirm this possibility. 


\section{Table 1. Relative Solution Impurity Levels (ppb)}

Tank B Solution Impurity Levels (solution \#980130)

\begin{tabular}{|c|c|c|c|c|c|c|c|}
\hline Date & $\mathrm{Si}$ & $\mathrm{B}$ & $\mathrm{Ca}$ & $\mathrm{Al}$ & $\mathrm{Fe}$ & $\mathrm{Cr}$ & $\mathrm{Ba}$ \\
\hline & $(300)$ & $(300)$ & $(100)$ & $(100)$ & $(20)$ & $(50)$ & $(10)$ \\
\hline $10 / 13$ & 66000 & 7300 & 510 & 240 & 91 & $\mathrm{ND}$ & 26 \\
\hline $10 / 19$ & 69000 & 7700 & 530 & 370 & 96 & $\mathrm{ND}$ & 28 \\
\hline $10 / 27$ & 71000 & 6500 & 750 & 320 & 110 & $\mathrm{ND}$ & 27 \\
\hline $11 / 2$ & 73000 & 6500 & 640 & 430 & 120 & $\mathrm{ND}$ & 23 \\
\hline $11 / 9$ & 77000 & 8700 & 710 & 550 & 120 & $\mathrm{ND}$ & 29 \\
\hline $11 / 16$ & 77000 & 9500 & 650 & 510 & 110 & $\mathrm{ND}$ & 35 \\
\hline $11 / 23$ & 80000 & 10000 & 650 & 530 & 130 & $\mathrm{ND}$ & 22 \\
\hline $12 / 1$ & 85000 & 11000 & 690 & 520 & 110 & $\mathrm{ND}$ & 24 \\
\hline $12 / 8$ & 93000 & 11000 & 730 & 510 & 100 & $\mathrm{ND}$ & 27 \\
\hline
\end{tabular}

Tank C Solution Impurity Levels (solution \#980528)

\begin{tabular}{|c|c|c|c|c|c|c|c|}
\hline Date & $\mathrm{Si}$ & $\mathrm{B}$ & $\mathrm{Ca}$ & $\mathrm{Al}$ & $\mathrm{Fe}$ & $\mathrm{Cr}$ & $\mathrm{Ba}$ \\
\hline & $(300)$ & $(300)$ & $(100)$ & $(100)$ & $(20)$ & $(50)$ & $(10)$ \\
\hline $11 / 7$ & 39000 & 4400 & 360 & 1300 & 260 & $\mathrm{ND}$ & 37 \\
\hline $11 / 16$ & 46000 & 6700 & 300 & 1500 & 240 & $\mathrm{ND}$ & 34 \\
\hline $11 / 23$ & 52000 & 6900 & 300 & 1600 & 250 & $\mathrm{ND}$ & 28 \\
\hline $12 / 1$ & 61000 & 7700 & 390 & 1800 & 300 & $\mathrm{ND}$ & $\mathrm{D}$ \\
\hline $12 / 8$ & 76000 & 8600 & 320 & 1500 & 250 & $\mathrm{ND}$ & 25 \\
\hline
\end{tabular}

Tank D Solution Impurity Levels (solution \#981113)

\begin{tabular}{|c|c|c|c|c|c|c|c|}
\hline Date & $\mathrm{Si}$ & $\mathrm{B}$ & $\mathrm{Ca}$ & $\mathrm{Al}$ & $\mathrm{Fe}$ & $\mathrm{Cr}$ & $\mathrm{Ba}$ \\
\hline & $(300)$ & $(300)$ & $(100)$ & $(100)$ & $(20)$ & $(50)$ & $(10)$ \\
\hline $11 / 20$ & 4800 & 1400 & $\mathrm{ND}$ & $\mathrm{D}$ & 96 & $\mathrm{ND}$ & 97 \\
\hline $12 / 1$ & 17000 & 1800 & $\mathrm{ND}$ & 560 & 150 & $\mathrm{ND}$ & 140 \\
\hline $12 / 8$ & 25000 & 2400 & $\mathrm{D}$ & 950 & 200 & $\mathrm{ND}$ & 120 \\
\hline
\end{tabular}


Tank F Solution Impurity Levels (solution \#981013)

\begin{tabular}{|c|c|c|c|c|c|c|c|}
\hline Date & $\mathrm{Si}$ & $\mathrm{B}$ & $\mathrm{Ca}$ & $\mathrm{Al}$ & $\mathrm{Fe}$ & $\mathrm{Cr}$ & $\mathrm{Ba}$ \\
\hline & $(300)$ & $(300)$ & $(100)$ & $(100)$ & $(20)$ & $(50)$ & $(10)$ \\
\hline $10 / 26$ & 5500 & 650 & 230 & $\mathrm{ND}$ & 120 & $\mathrm{ND}$ & 43 \\
\hline $11 / 2$ & 18000 & 1600 & 370 & 570 & 140 & $\mathrm{ND}$ & 50 \\
\hline $11 / 9$ & 27000 & 3000 & $\mathrm{D}$ & 920 & 150 & $\mathrm{ND}$ & 50 \\
\hline $11 / 16$ & 35000 & 4500 & 260 & 1100 & 140 & $\mathrm{ND}$ & $\mathrm{D}$ \\
\hline $11 / 23$ & 44000 & 5400 & 290 & 1200 & 150 & $\mathrm{ND}$ & $\mathrm{D}$ \\
\hline $12 / 1$ & 55000 & 6600 & 320 & 840 & 120 & $\mathrm{ND}$ & $\mathrm{ND}$ \\
\hline $12 / 8$ & 70000 & 8400 & 300 & 400 & 62 & $\mathrm{ND}$ & 25 \\
\hline
\end{tabular}




\section{Table 2. Absolute Solution Impurity Levels (grams)}

Tank B Solution Impurity Levels (solution \#980130)

\begin{tabular}{|c|l|l|l|l|l|l|l|}
\hline Date & \multicolumn{1}{|c|}{$\mathrm{Si}$} & \multicolumn{1}{c|}{$\mathrm{B}$} & \multicolumn{1}{c|}{$\mathrm{Ca}$} & $\mathrm{Al}$ & $\mathrm{Fe}$ & $\mathrm{Cr}$ & $\mathrm{Ba}$ \\
\hline & & & & & & & \\
\hline $10 / 13$ & 32.23 & 3.565 & 0.249 & 0.1172 & 0.04444 & 0.000 & 0.0127 \\
\hline $10 / 19$ & 33.69 & 3.76 & 0.2588 & 0.1807 & 0.04688 & 0.000 & 0.01367 \\
\hline $10 / 27$ & 34.64 & 3.171 & 0.3659 & 0.1561 & 0.05367 & 0.000 & 0.01317 \\
\hline $11 / 2$ & 35.48 & 3.159 & 0.3111 & 0.209 & 0.05833 & 0.000 & 0.01118 \\
\hline $11 / 9$ & 37 & 4.181 & 0.3412 & 0.2643 & 0.05767 & 0.000 & 0.01394 \\
\hline $11 / 16$ & 36.59 & 4.514 & 0.3089 & 0.2423 & 0.05227 & 0.000 & 0.01663 \\
\hline $11 / 23$ & 37.61 & 4.701 & 0.3056 & 0.2492 & 0.06111 & 0.000 & 0.01034 \\
\hline $12 / 1$ & 38.01 & 4.919 & 0.3085 & 0.2325 & 0.04919 & 0.000 & 0.01073 \\
\hline $12 / 8$ & 39.39 & 4.659 & 0.3092 & 0.216 & 0.04236 & 0.000 & 0.01144 \\
\hline
\end{tabular}

Tank C Solution Impurity Levels (solution \#980528)

\begin{tabular}{|c|l|l|l|l|l|l|l|}
\hline Date & \multicolumn{1}{|c|}{$\mathrm{Si}$} & \multicolumn{1}{c|}{$\mathrm{B}$} & \multicolumn{1}{c|}{$\mathrm{Ca}$} & $\mathrm{Al}$ & \multicolumn{1}{c|}{$\mathrm{Fe}$} & \multicolumn{1}{c|}{$\mathrm{Cr}$} & \multicolumn{1}{c|}{$\mathrm{Ba}$} \\
\hline & & & & & & & \\
\hline $11 / 7$ & 16.45 & 1.856 & 0.1518 & 0.5483 & 0.1097 & 0.000 & 0.01560 \\
\hline $11 / 16$ & 19.32 & 2.814 & 0.1260 & 0.63 & 0.1008 & 0.000 & 0.01428 \\
\hline $11 / 23$ & 21.24 & 2.818 & 0.1225 & 0.6535 & 0.1021 & 0.000 & 0.01144 \\
\hline $12 / 1$ & 23.02 & 2.906 & 0.1472 & 0.6793 & 0.1132 & 0.000 & 0.000 \\
\hline $12 / 8$ & 24.35 & 2.756 & 0.1025 & 0.4806 & 0.08011 & 0.000 & 0.00801 \\
\hline
\end{tabular}

Tank D Solution Impurity Levels (solution \#981113)

\begin{tabular}{|c|c|c|c|c|c|c|c|}
\hline Date & \multicolumn{1}{|c|}{$\mathrm{Si}$} & $\mathrm{B}$ & $\mathrm{Ca}$ & $\mathrm{Al}$ & $\mathrm{Fe}$ & $\mathrm{Cr}$ & $\mathrm{Ba}$ \\
\hline & & & & & & & \\
\hline $11 / 20$ & 1.991 & 0.5807 & 0.000 & 0.04148 & 0.03982 & 0.000 & 0.04024 \\
\hline $12 / 1$ & 7.031 & 0.7444 & 0.000 & 0.2316 & 0.06204 & 0.000 & 0.05790 \\
\hline $12 / 8$ & 10.05 & 0.9652 & 0.000 & 0.3821 & 0.08043 & 0.000 & 0.04826 \\
\hline
\end{tabular}


Tank F Solution Impurity Levels (solution \#981013)

\begin{tabular}{|c|l|l|l|l|l|l|l|}
\hline Date & \multicolumn{1}{|c|}{$\mathrm{Si}$} & \multicolumn{1}{c|}{$\mathrm{B}$} & \multicolumn{1}{c|}{$\mathrm{Ca}$} & $\mathrm{Al}$ & $\mathrm{Fe}$ & $\mathrm{Cr}$ & $\mathrm{Ba}$ \\
\hline & & & & & & & \\
\hline $10 / 26$ & 2.311 & 0.2731 & 0.09665 & 0.04202 & 0.05043 & 0.000 & 0.01807 \\
\hline $11 / 2$ & 7.564 & 0.6724 & 0.1555 & 0.2395 & 0.05883 & 0.000 & 0.02101 \\
\hline $11 / 9$ & 11.10 & 1.234 & 0.000 & 0.3783 & 0.06168 & 0.000 & 0.02056 \\
\hline $11 / 16$ & 13.67 & 1.758 & 0.1016 & 0.4297 & 0.05469 & 0.000 & 0.000 \\
\hline $11 / 23$ & 15.56 & 1.910 & 0.1026 & 0.4244 & 0.05305 & 0.000 & 0.000 \\
\hline $12 / 1$ & 16.42 & 1.970 & 0.09551 & 0.2507 & 0.03582 & 0.000 & 0.000 \\
\hline $12 / 8$ & 16.91 & 2.029 & 0.07246 & 0.09661 & 0.01497 & 0.000 & 0.00603 \\
\hline
\end{tabular}



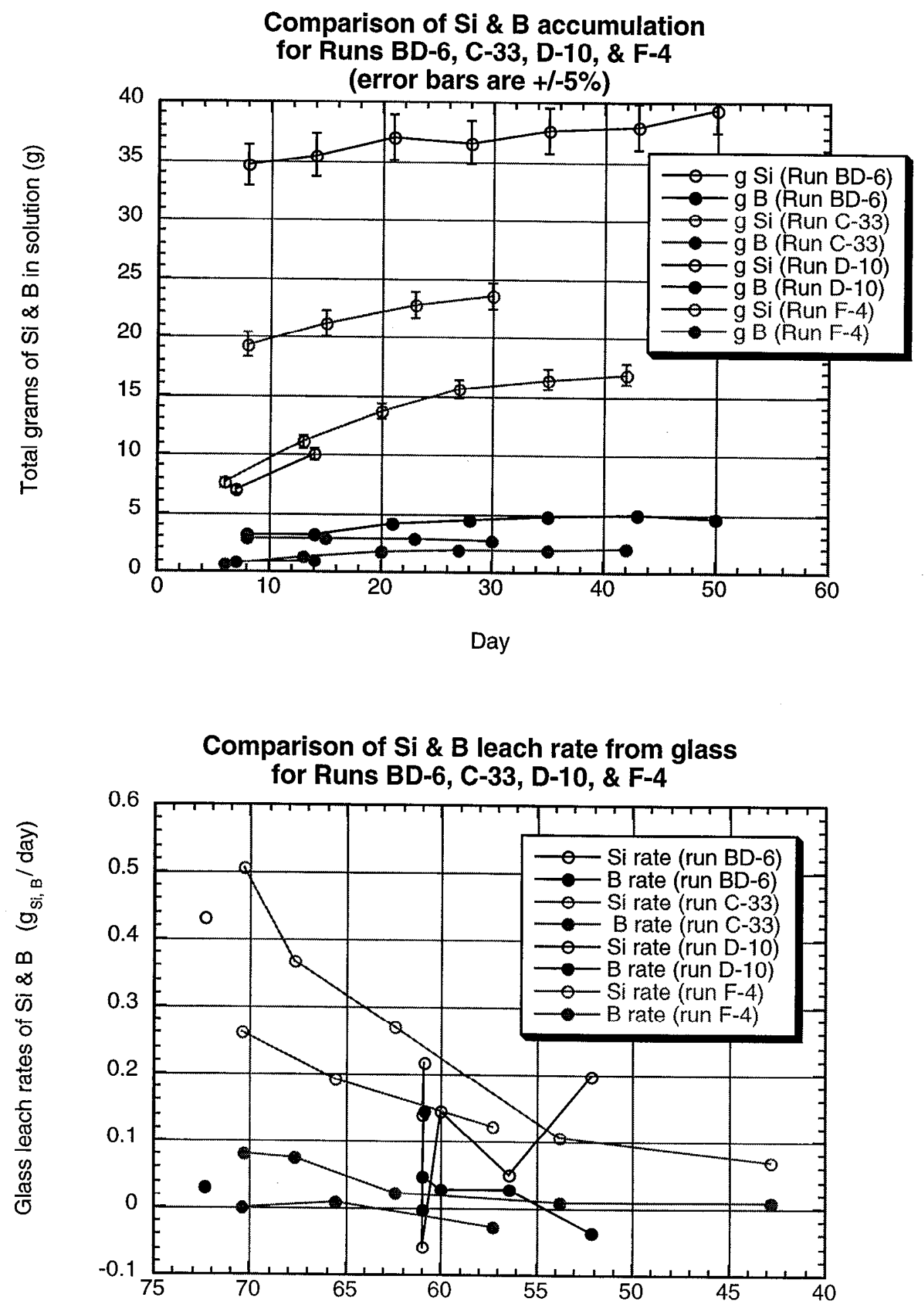

Temperature $\left({ }^{\circ} \mathrm{C}\right)$

Figure 1 


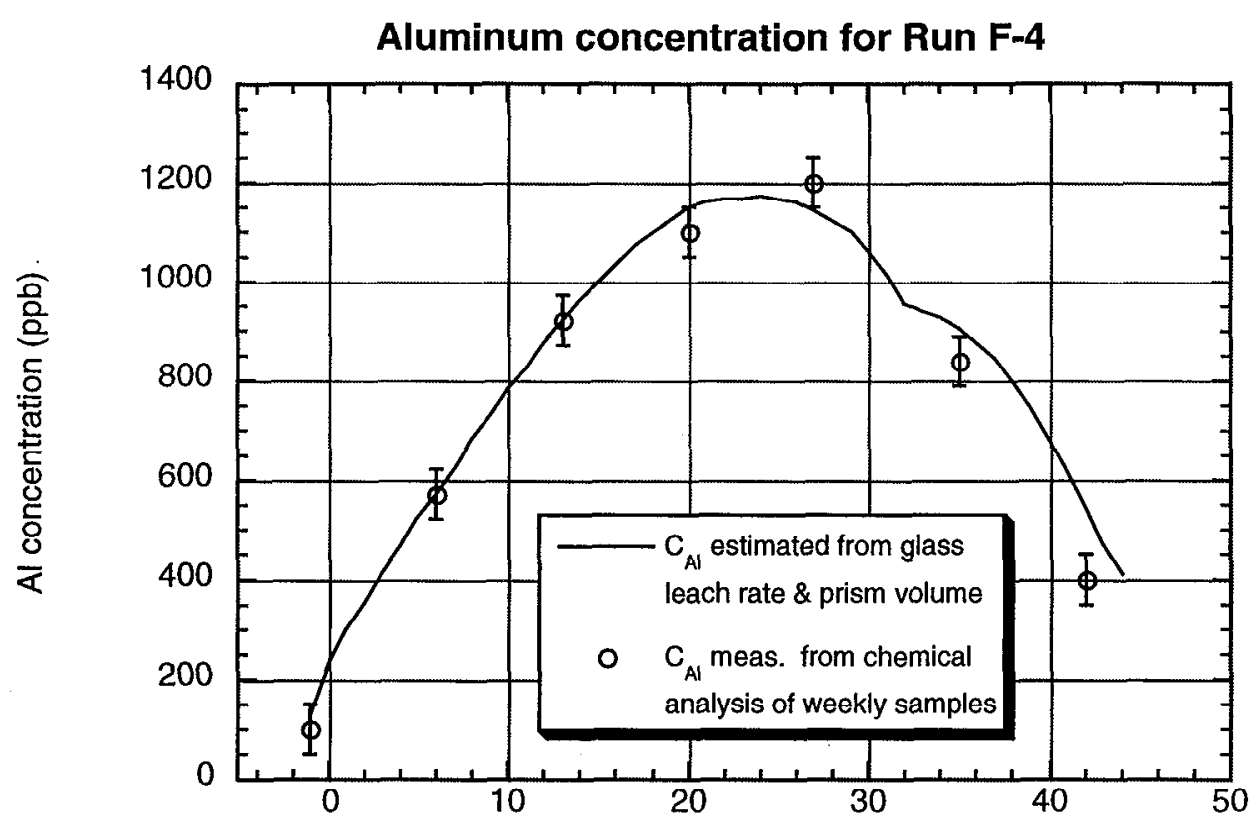

Day

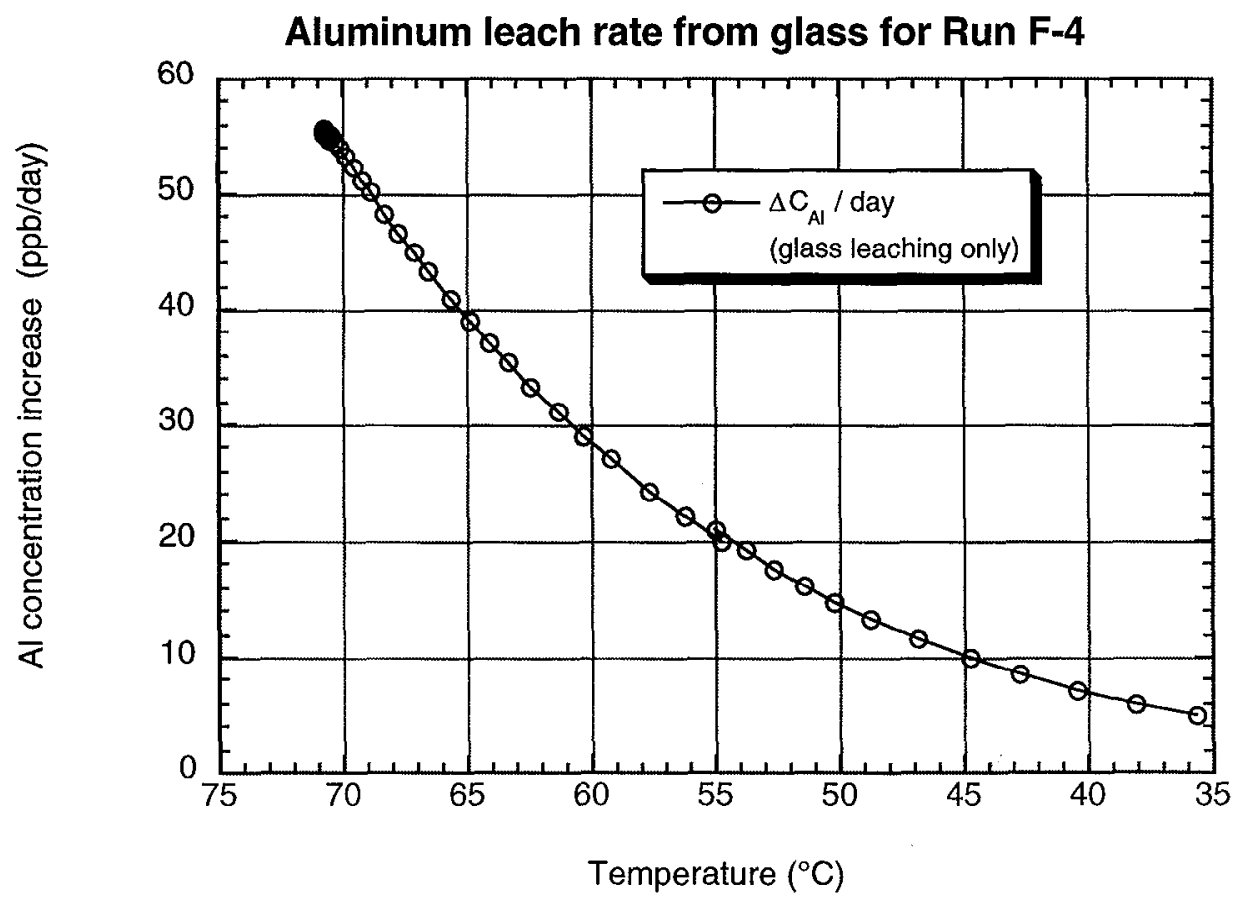

Figure 2 

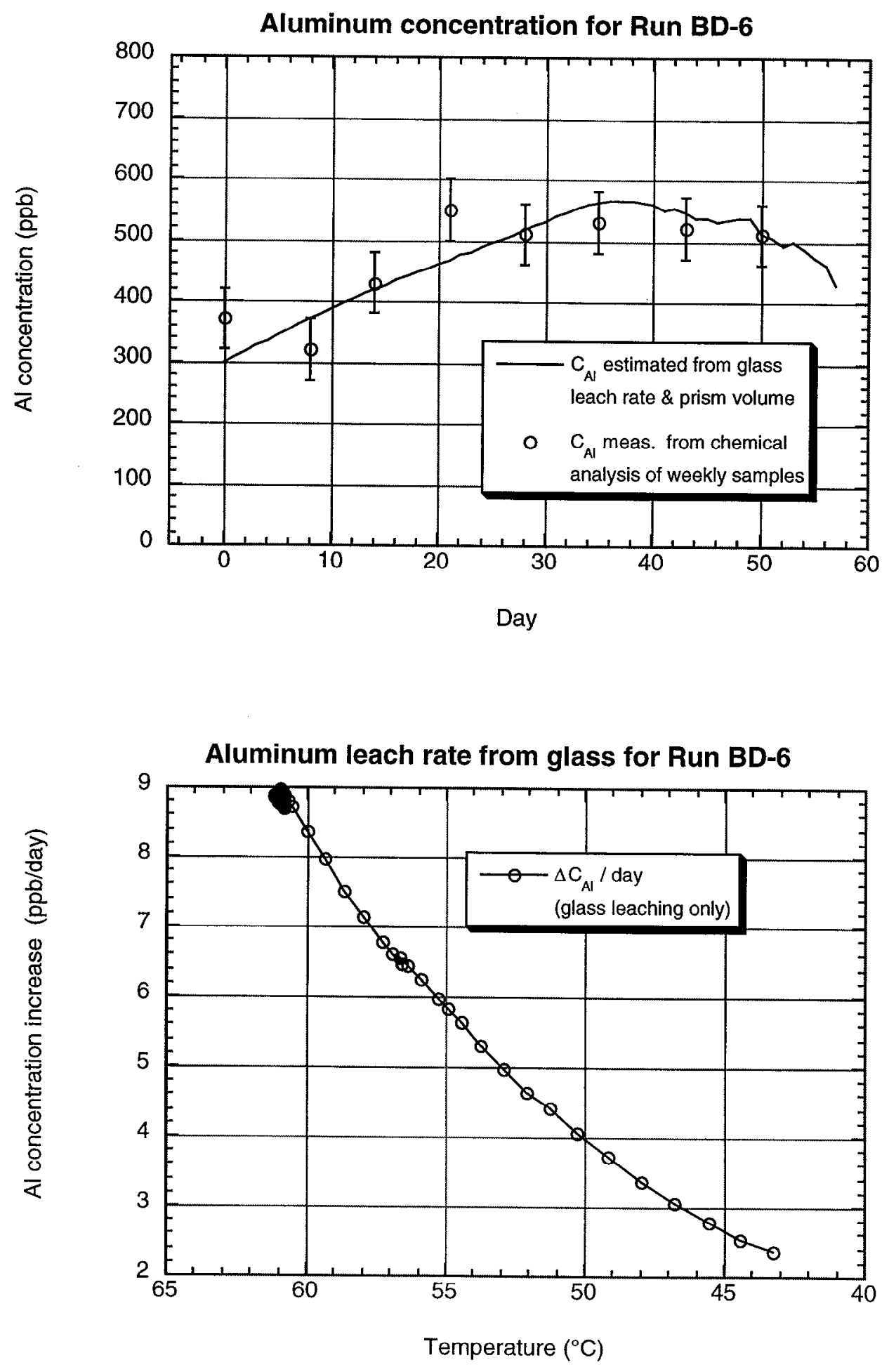

Figure 3 

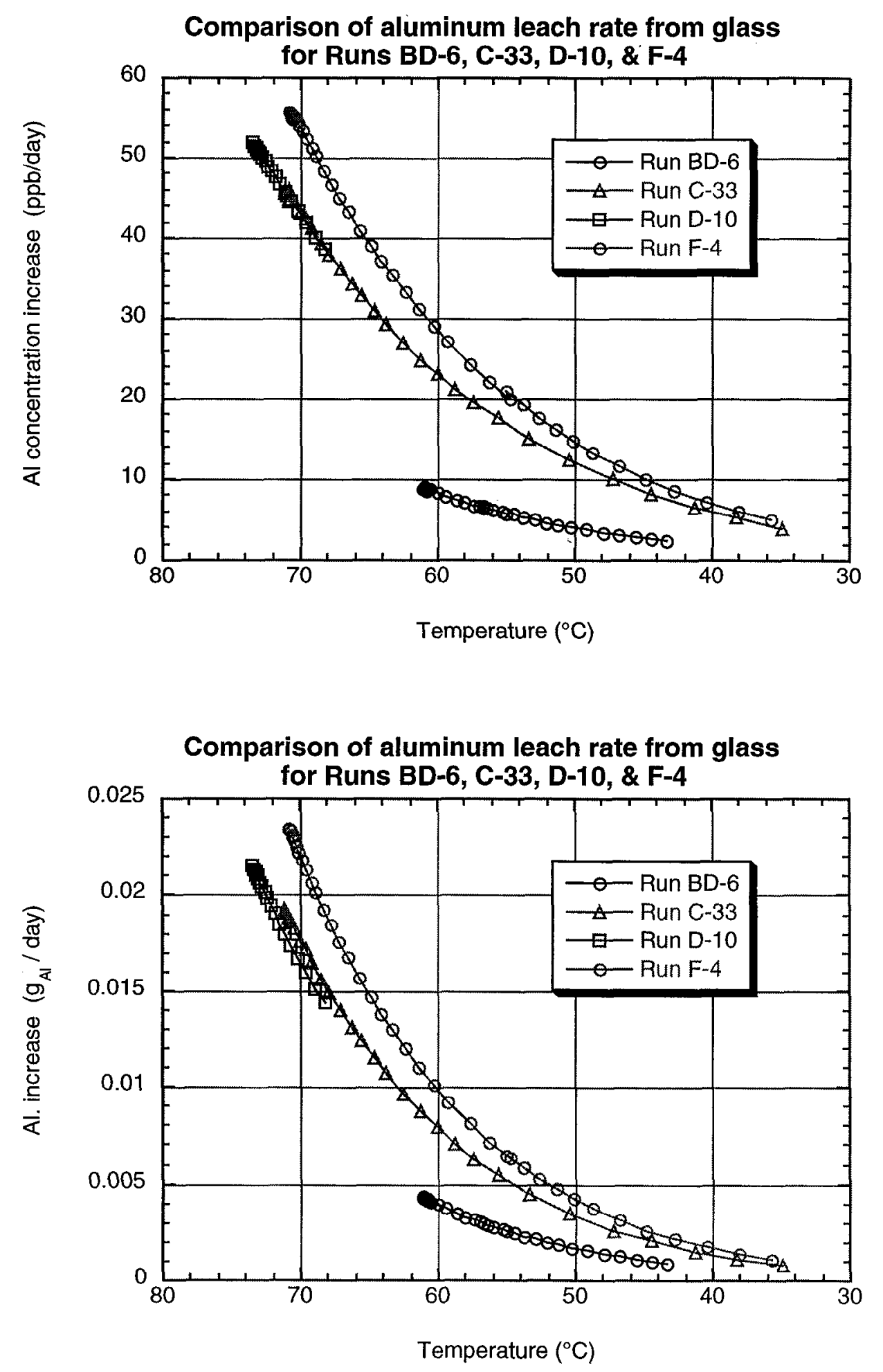

Figure 4 

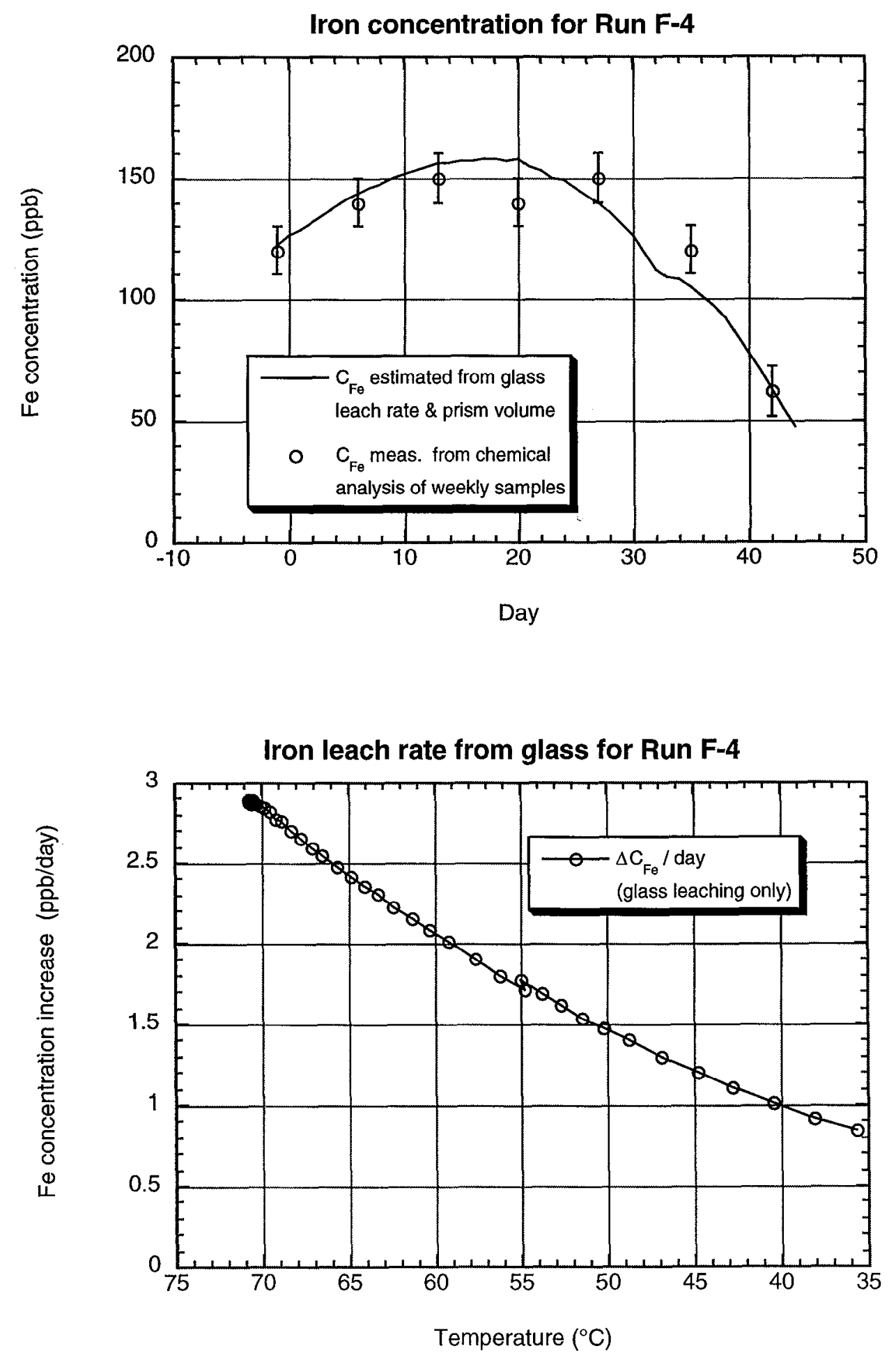

Figure 5 

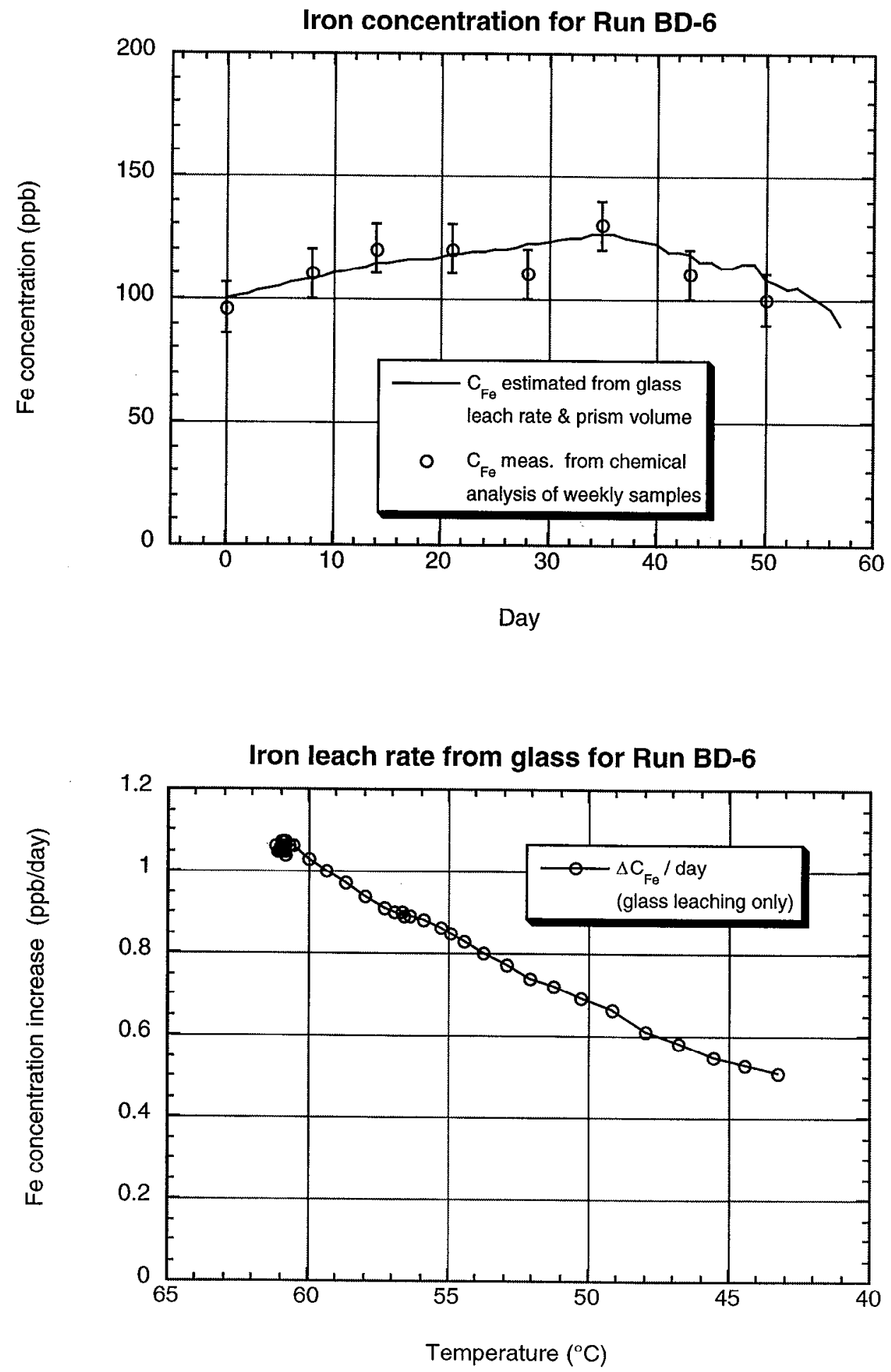

Figure 6 

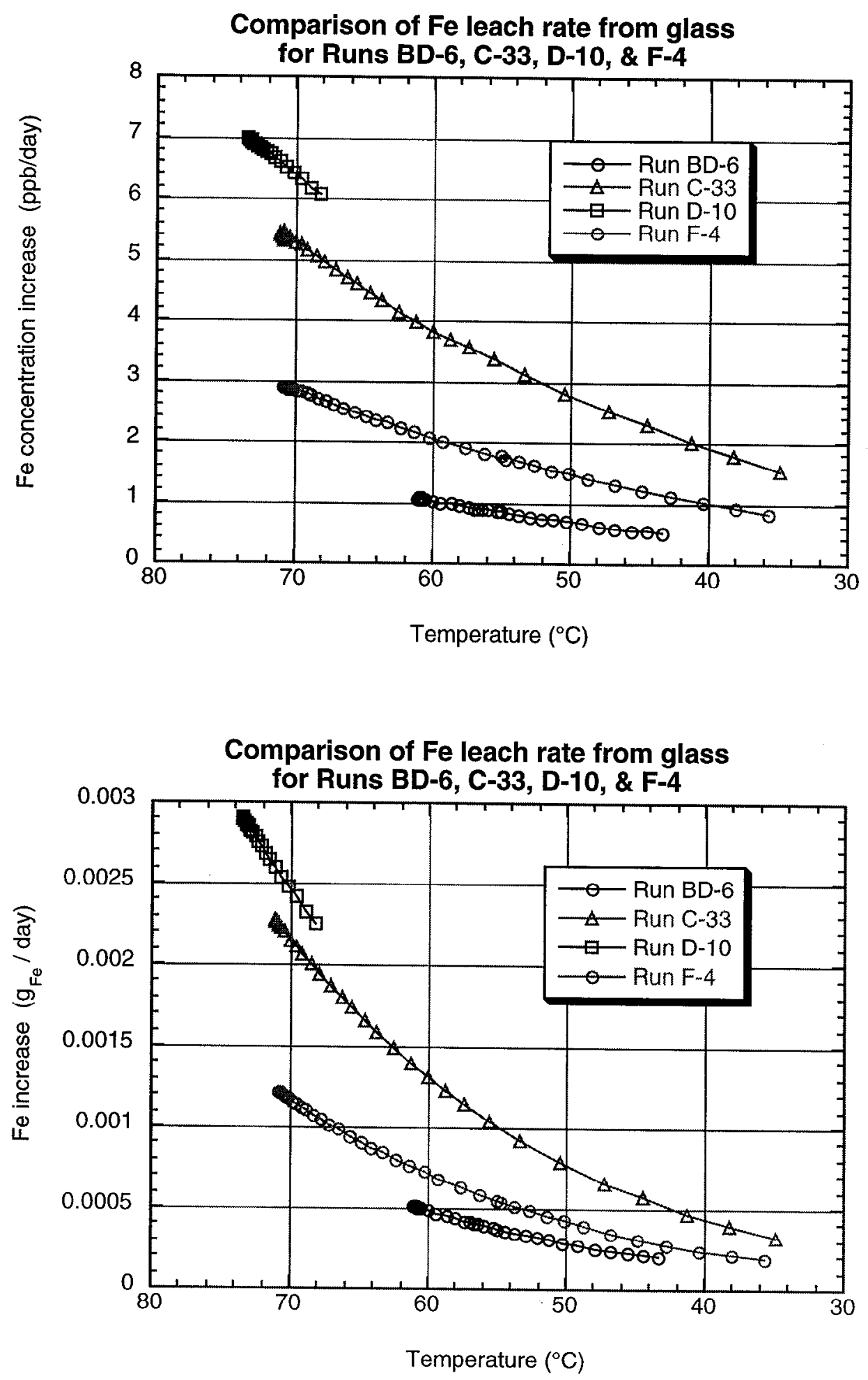

Figure 7 
Ca accumulation for Runs BD-6, C-33, D-10, \& F-4 (error bars are +/- MDL / 2)

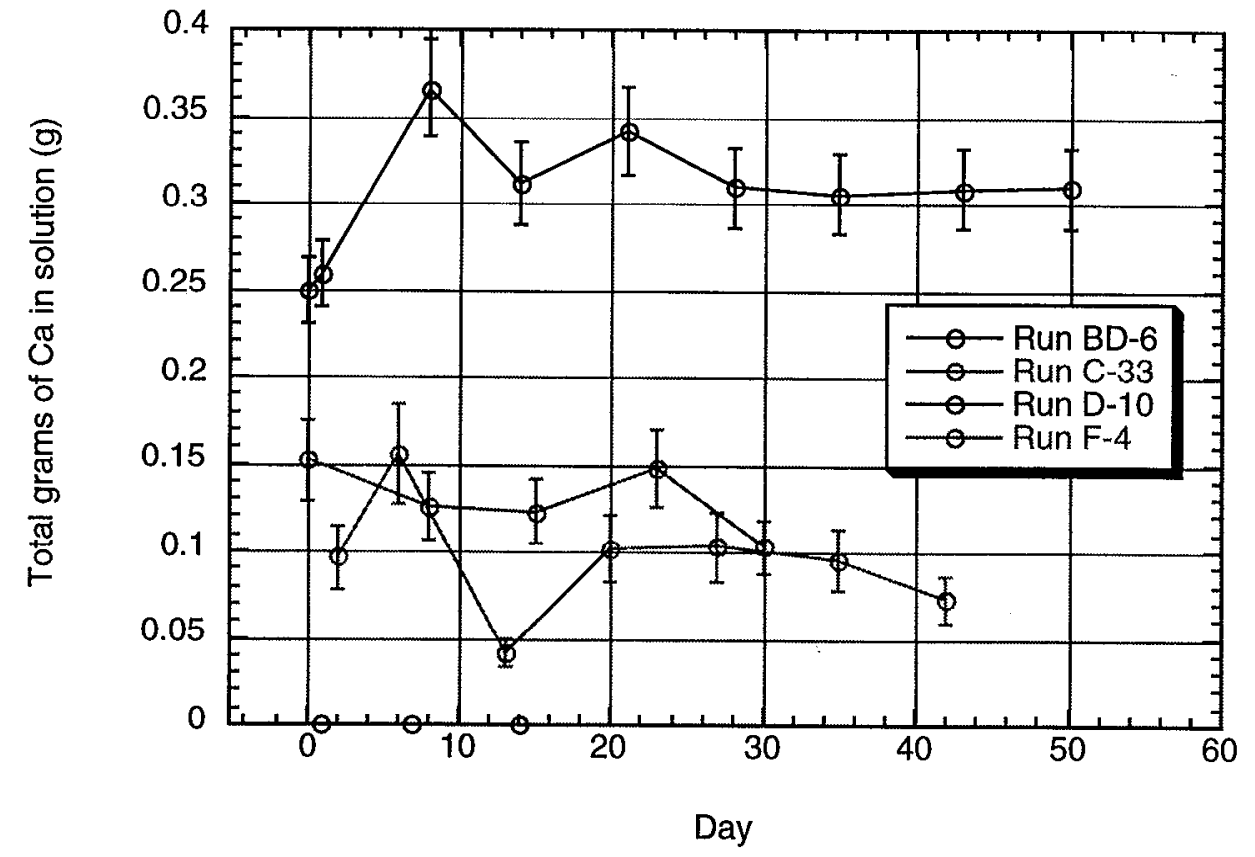

Figure 8 


\section{Appendix}
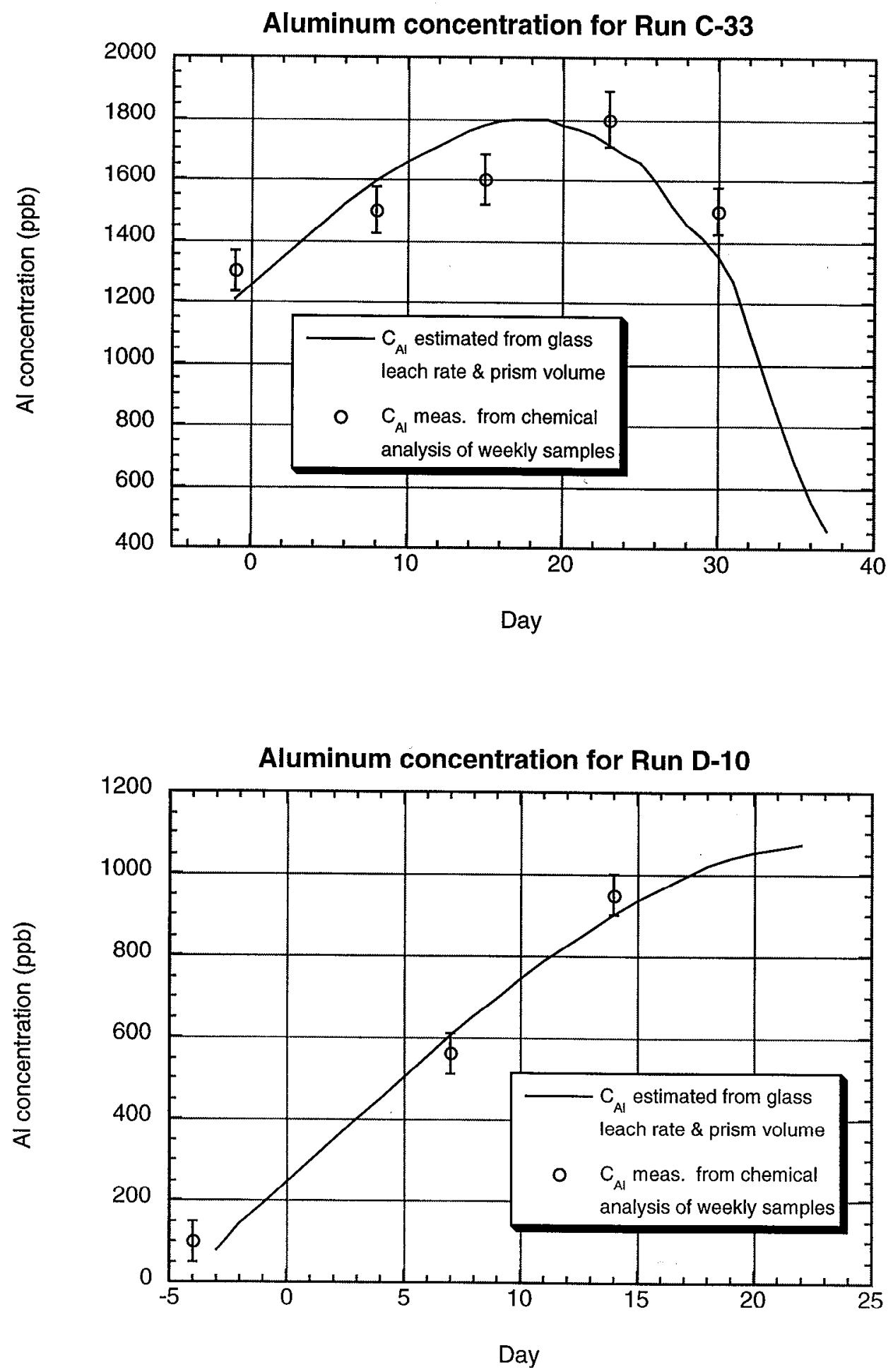

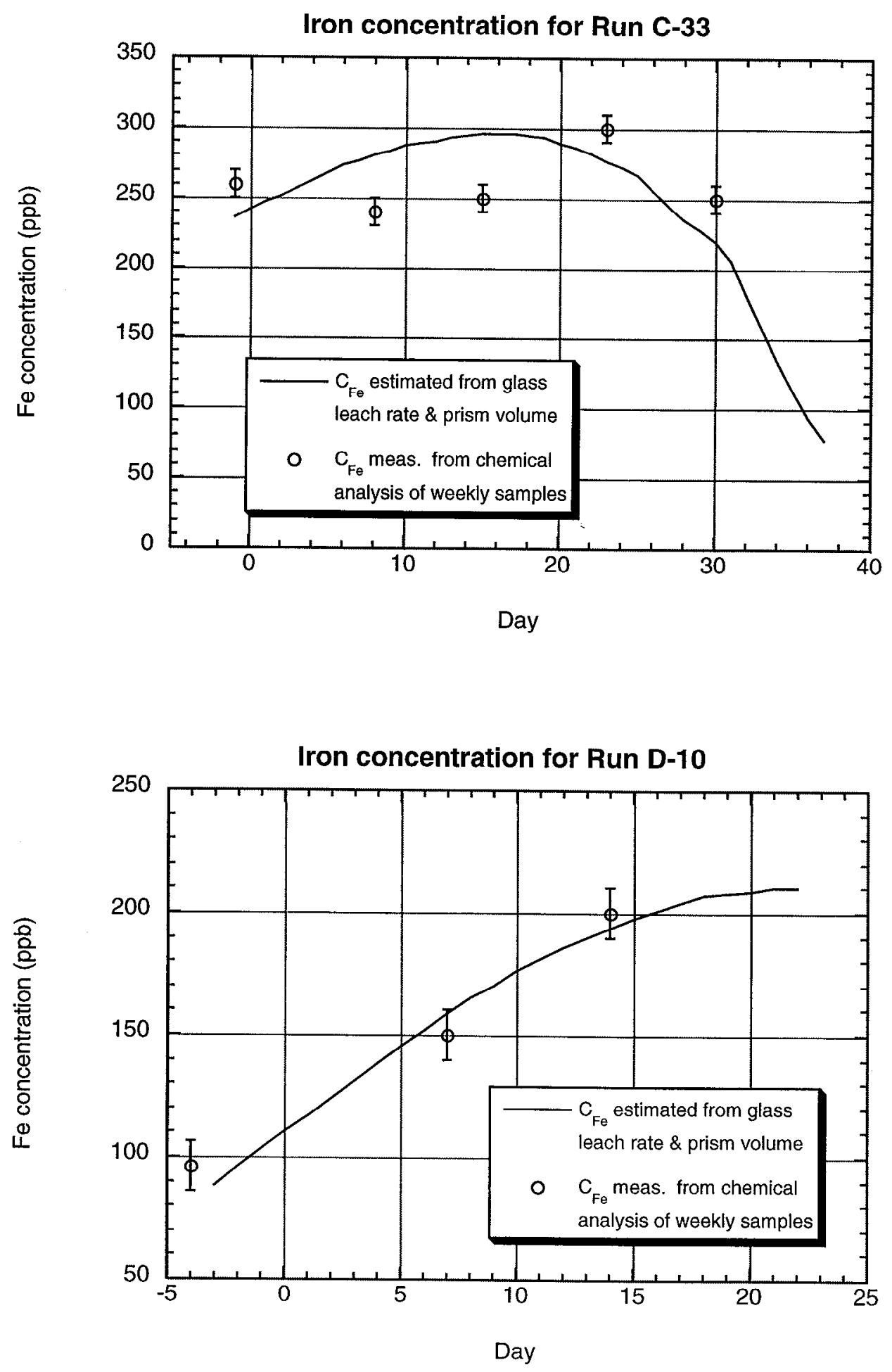


\section{References}

1.) N. Zaitseva, L. Carman, I Smolsky, R. Torres, and M. Yan "The effect of impurities and supersaturation on the rapid growth of KDP crystals," submitted to the Journal of Crystal Growth (1998).

2.) J. DeYoreo, personal communication (1998).

3.) H. Robey, R. Hawley-Fedder, R. Floyd, M. DeHaven, and R. Rozsa, "The LINL KDP Crystal Growth Electronic Log Book," LLNL internal document (1998).

4.) M. Yan, R. Torres, M. Runkel, B. Woods, I. Hutcheon, N. Zaitseva, and J. DeYoreo, "Impurity and laser-induced damage in the growth sectors of rapidly grown KDP crystals," Proc. SPIE Laser-Induced Damage in Optical Materials: 1996, Vol. 2966 (1996).

5.) H. Robey, M. DeHaven, C. Steffani, I. Fine, W. Olund, \& D. Schumann, "A controlled study of KDP solution contamination from Halar-coated aluminum growth platforms," LLNL internal document, in preparation (Jan., 1999).

6.) L. Rashkovich, "Effect of $\mathrm{pH}$ on the growth of KDP," UCRL-CR-122742-1 (March, 1998). 